\title{
Desreguladores Endócrinos: \\ Efeitos Adversos e Estratégias para Monitorização dos Sistemas Aquáticos
}

$\mathrm{H}_{\mathrm{a}}$

UMA PREOCUPAÇÃO CRESCENTE COM A acção perturbadora que diversos poluentes orgânicos desencadeiam ao nivel do sistema endócrino dos animais. A constatação repetida de efeitos nefastos, causados em várias populações da fauna selvagem e até no próprio Homem, foi o ponto de partida para a eclosão mundial de inúmeras pesquisas em busca dos designados desreguladores endócrinos. Manifestam-se, genericamente, ao nível do sistema endócrino, causando efeitos adversos na saúde, alterações do comportamento e anomalias na função reprodutiva.

Neste contexto, é urgente alertar a opinião pública para os riscos associados à exposição e bioacumulação deste tipo de substâncias e realçar a enorme importância na monitorização dos sistemas aquáticos, que são os principais veículos de dispersão ambiental.

\section{Introdução}

Desregulador ou disruptor endócrino (endocrine disruptor) é o termo associado a toda a substância ou mistura de substâncias exógenas, capazes de assumir idêntica função de uma hormona natural nos seres vivos ou inibir o funcionamento normal da mesma, alterando as funções do sistema endócrino e consequentemente, prejudicar a saúde do organismo, da sua progenitura ou de uma (sub)população. Estas substâncias, são na sua maioria poluentes químicos e derivados de químicos antropogénicos, provenientes de pesticidas, plásticos, detergentes, lacas, tintas e outros materiais vulgarmente usados ou que constituem diversos tipos de resíduos industriais ou domésticos. Genericamente, são compostos muito estáveis, lipofílicos e semi-voláteis, também designados por poluentes orgânicos persistentes, o que facilita a rápida e vasta dispersão ambiental, tendo como principais veículos os recursos hídricos e zonas marítimas.

A função hormonal que mais vulgarmente é afectada por estes agentes artificiais é o mecanismo de regulação dos esteróides, que maioritariamente determinam as características sexuais e o comportamento das espécies, sendo já uma evidência a enorme preocupação internacional relativamente à saúde pública e ambiental.

O despertar para esta problemática com repercussões de várias ordens surgiu concretamente nos grandes lagos, devido ao ressurgimento de elevados níveis de poluição, afectando espécies particulares de peixes, aves e répteis entre outras.

\section{O sistema endócrino}

O sistema endócrino é uma complexa rede de sinais e mensagens químicas que controla as funções e reacções corporais em quase todos os animais, vertebrados (mamíferos, peixes, anfibios, répteis e aves) e invertebrados (moluscos e insectos), interagindo directamente com o sistema nervoso [1].
No Homem, é constituído por três partes distintas, nomeadamente, por um conjunto de glândulas especializadas, como o hipotálamo, as glândulas pituitárias, a tiróide e paratiróide, as adrenais, o pâncreas e as gónadas entre outras, por mensageiros químicos também designados hormonas, sintetizadas e segregadas nas glândulas e finalmente por células alvo, que recebem as hormonas e desta forma respondem às necessidades corporais.

Genericamente, o hipotálamo regula as glândulas pituitárias ou hipófise (anterior e posterior) situadas junto ao cérebro, que por sua vez controlam diversas funções, concretamente a secreção das gónadas (testículos nos machos e ovários nas fêmeas), as glândulas tiróide, paratiróide e adrenais, as quais estimulam ou controlam respectivamente o crescimento, a temperatura, a formação óssea, o balanço salino, entre outras funções orgânicas. 0 pâncreas segrega hormonas que controlam o sistema digestivo, nomeadamente insulina, glucagina e outro tipo de substâncias reguladoras dos níveis de glucose, glicogénio e lípidos. Os ovários e os testículos controlam as funções sexuais características, o comportamento e as hormonas sexuais libertadas que incluem o estrogénio (17 $\beta$-estradiol) e o androgénio (testosterona), respectivamente.

0 mecanismo de accionamento do sistema endócrino tem início na reacção das células nervosas a determinado estímulo (ex. fome, medo ou a alteração 
da temperatura corporal), enviando posteriormente um sinal às glândulas endócrinas. Estas, por sua vez, libertam as hormonas adequadas que levarão instruções para células alvo onde se ligarão a receptores específicos que se localizam no núcleo. 0 receptor interpreta então, a mensagem hormonal e faz a tradução mediante um de dois processos celulares distintos: (i) ordena aos genes que produzam novas proteínas, o que causa efeitos a longo prazo, como é o caso por exemplo do crescimento ou maturação sexual e reprodutiva; (ii) altera a actividade de proteínas existentes na célula, provocando uma resposta rápida por parte do organismo, que se repercute por exemplo no aumento do ritmo cardíaco ou na variação do nível de açúcar no sangue.

\section{Tipo de hormonas}

As hormonas são substâncias de sinalização que viajam através da corrente sanguínea e suscitam respostas noutras partes do corpo [2]. Nos animais podem genericamente ser diferenciadas em dois tipos, dependendo da forma como são transmitidas e recebidas pelas células alvo: (i) as hormonas proteicas, não esteróides, requerem emissores/receptores para se transferirem de uma célula para outra, visto serem muito pouco solúveis na membrana celular lípidica pelo facto de serem geralmente constituídas por proteinas modificadas e apre- sentarem carga na estrutura; (ii) as hormonas esteróides que derivam do colesterol, não necessitam destes emissores/receptores para atravessarem a membrana celular e difundir-se nas células, onde irão desempenhar acções intracelulares importantes (ex. sintese proteica), uma vez serem de menor dimensão e substancialmente lipofilicas.

As hormonas esteróides circulam livremente entre células alvo, interagindo posteriormente no seu interior com receptores nucleares muito específicos, formando complexos como se de um modelo de "chave-fechadura" se tratasse. A figura 1 exemplifica simplificadamente o mecanismo relativo à recepção e ligação das hormonas esteróides a receptores nucleares específicos nas células alvo. São essenciais para a saúde dos organismos tendo uma influência particularmente importante no respectivo metabolismo. Por exemplo, o estradiol é a hormona responsável pela formação das características femininas, comportamento sexual, ciclos menstruais e ovulação. Além disso, influencia a formação óssea, sistema cardiovascular, memória, pele e sistema imunitário. Já a testosterona é a hormona responsável pelas características sexuais masculinas, estando por exemplo associada à produção de esperma.

As hormonas esteróides, também designadas por esteróides sexuais, regulam fundamentalmente a diferenciação se- xual e são de extrema importância para o desenvolvimento embrionário dos animais. É exactamente pela enorme importância biológica destes esteróides que muitos dos químicos sintetizados pelo Homem podem ser nocivos, imitando ou mesmo bloqueando a acção das hormonas naturais dado que apresentam estruturas e funcionalidades muito semelhantes. As hormonas proteicas estão mais resguardadas a este fenómeno, uma vez apresentarem um mecanismo de actuação muito mais complexo.

Deve salientar-se que o sistema hormonal nos organismos é estimulado com pequeníssimas concentrações de esteróides, da ordem das partes por bilião (ppb) ou mesmo partes por trilião (ppt), sendo essa a principal razão porque traços ou teores vestigiais de químicos orgânicos exógenos poderem ser tão perniciosos.

\section{Desreguladores endócrinos}

A grande maioria dos desreguladores endócrinos que no ambiente imitam a família das hormonas esteróides femininas ou estrogénios, são designados por xeno-estrogénios (estrogénios estranhos) ou eco-estrogénios (estrogénios ambientais). Os xeno-estrogénios são assim substâncias que afectam o sistema endócrino dos animais, alterando o desenvolvimento e/ou a reprodução dos organismos, não sendo no entanto gera-

figura 1 Mecanismo simplificado de recepção e ligação das hormonas esteróides aos receptores nucleares especificos das células alvo; a) 17ß-estradiol; b) testosterona.

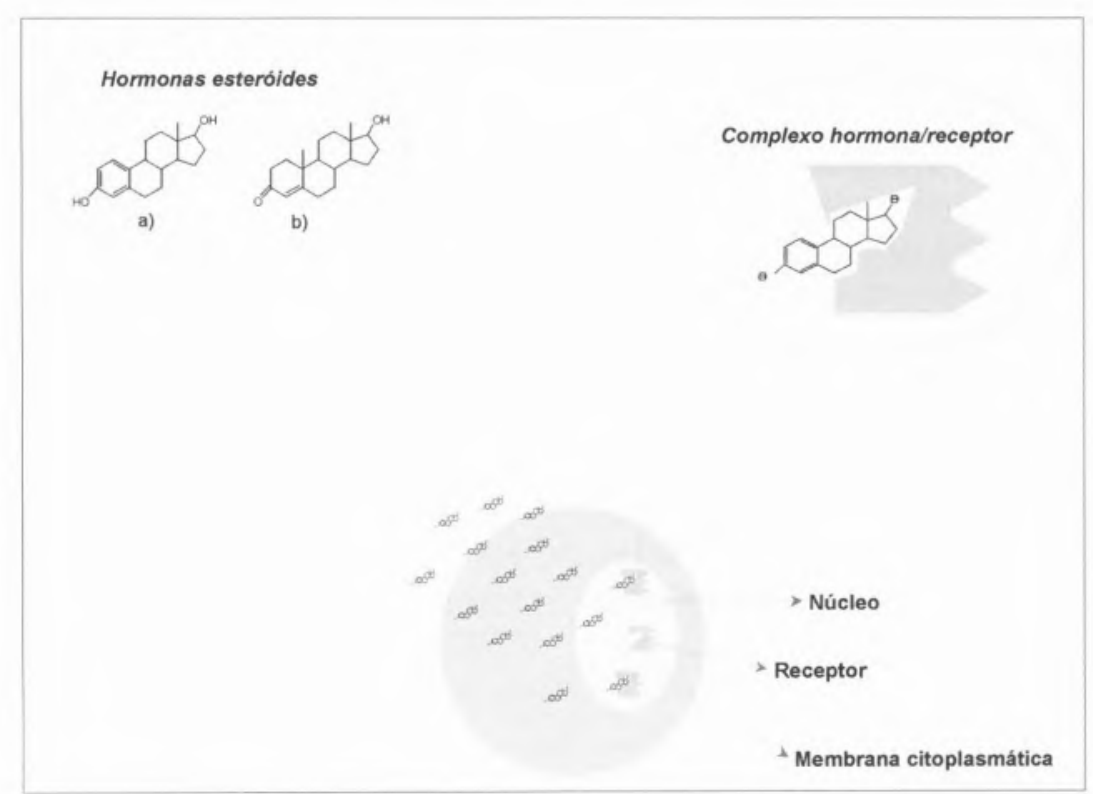


Tabela 1

Evolução cronológica dos factos e evidências relativa aos efeitos adversos causados pelos xeno-estrogénios.

1923 Detecta-se actividade estrogénica em extractos biológicos

1950 Observa-se que o DDT evidencia actividade estrogénica

1962 Surgem as primeiras correlações entre os pesticidas/químicos sin téticos e os problemas de saúde ambiental observadas na vida sel vagem

1963 Verifica-se que a exposição a hormonas naturais é perigosa e conduz ao cancro

1968 Descobre-se que o DDT apresenta actividade estrogénica nos mamífe ros e aves

1971 Verifica-se que o diclorodifenildicloro etano (DDE) está na origem do cancro vaginal, sobretudo em mulheres cujas mães estiveram expos tas a este produto durante a gravidez

1972 O DDT é proibido na agricultura

1976 Verifica-se que o DDE está interligado a problemas na reprodução hu mana

1977 A produção e aplicação de bifenilos policlorados (PCBs) é restringida

1980 A utilização de certas hormonas sintéticas é restringida

1993 Detecta-se relação entre os xeno-estrogénios e problemas no aparelho reprodutivo masculino e feminino

1996 Verifica-se que combinações de diversos xeno-estrogénios apresentam sinergismos em diverso tipo de leveduras

1998 Começam a forma-se os primeiros grupos de investigação a nível mun dial para estudar e dar resposta a esta problemática

1999 Desenvolvem-se estudos in-vitro e in-vivo conducentes à elaboração de listas de substâncias classificadas como contendo potencial actividade estrogénica

dos ou produzidos por esses mesmos organismos. A Tabela 1 apresenta a evolução cronológica dos factos e evidências que conduziram às suspeitas quanto aos efeitos adversos causados pelos xeno-estrogénios. Constata-se que o diclorodifeniltricloro etano (DDT) foi o precursor relativamente à observação das anomalias observadas em animais, tendo surgido posteriormente outras substâncias.

Os desreguladores endócrinos encontram-se principalmente entre classes de compostos com origem em produtos ou sub-produtos químicos industriais, pesti- cidas e biocidas, produtos naturais e hormonas sintéticas, nomeadamente [3]:

- Ftalatos: Muito usados como plasticizantes aditivos na constituição dos plásticos e outros polímeros (ex. dibutilftalato);

- Fenóis: Surfactantes usados como detergentes (ex. p-nonilfenol), componentes constituintes de resinas (ex. bisfenol A) e clorofenóis (ex. 2,4,6, triclorofenol);

- Hidrocarbonetos policíclicos aromáticos policiclícos (PAHS): Provenientes de fontes naturais, nomeadamente de erupções vulcânicas, fogos, etc. e de fontes antropogénicas como da queima de combustíveis fósseis e incineração de resíduos (ex. benzo[a]pireno);

- Bifenilos policlorados (PCBS) e dioxinas: Grupo de compostos que genericamente estão associados e têm origem em diversos processos industriais ou resultam como subprodutos da coincineração (ex. 2,3,7,8 -TCDD);

- Pesticidas e biocídas: Incluem-se diversos tipos de compostos muito utilizados especialmente na agricultura, nomeadamente, organoclorados (ex. DDT), organofosforados (ex. metil clorpirifos), propionamidas (ex. propanil), triazinícos (ex. atrazina) e organometálicos, como é o caso do cloreto de tributilo estanho (TBT) usado nas tintas antivegetativas para embarcações marítimas, entre outros;

- Produtos naturais: Com ocorrência em diversos tipos de plantas (ex. coumestrol);

- Hormonas sintéticas: Concretamente os componentes constituintes da pílula contraceptiva (ex. etinilestradiol) que são excretadas na urina numa forma conjugada e inactiva. Porém, aquando do tratamento de efluentes domésticos, as formas conjugadas são muito sensiveis a eventuais acções bacterianas, conferindo novamente actividade estrogénica às hormonas livres. Este grupo inclui igualmente hormonas usadas no passado e actualmente banidas dos circuitos comerciais (ex. dietilstilbestrol).

Em suma, os estrogénios endógenos, essencialmente o estradiol e a testosterona, competem com todo o tipo de potenciais estrogénios exógenos, fundamentalmente, estrogénios sintéticos (fármacos), fitoestrogénios (produtos naturais) e xeno-estrogénios (químicos industriais), uma vez evidenciarem substanciais semelhanças quer ao nível estrutural quer funcional (figura 2). 


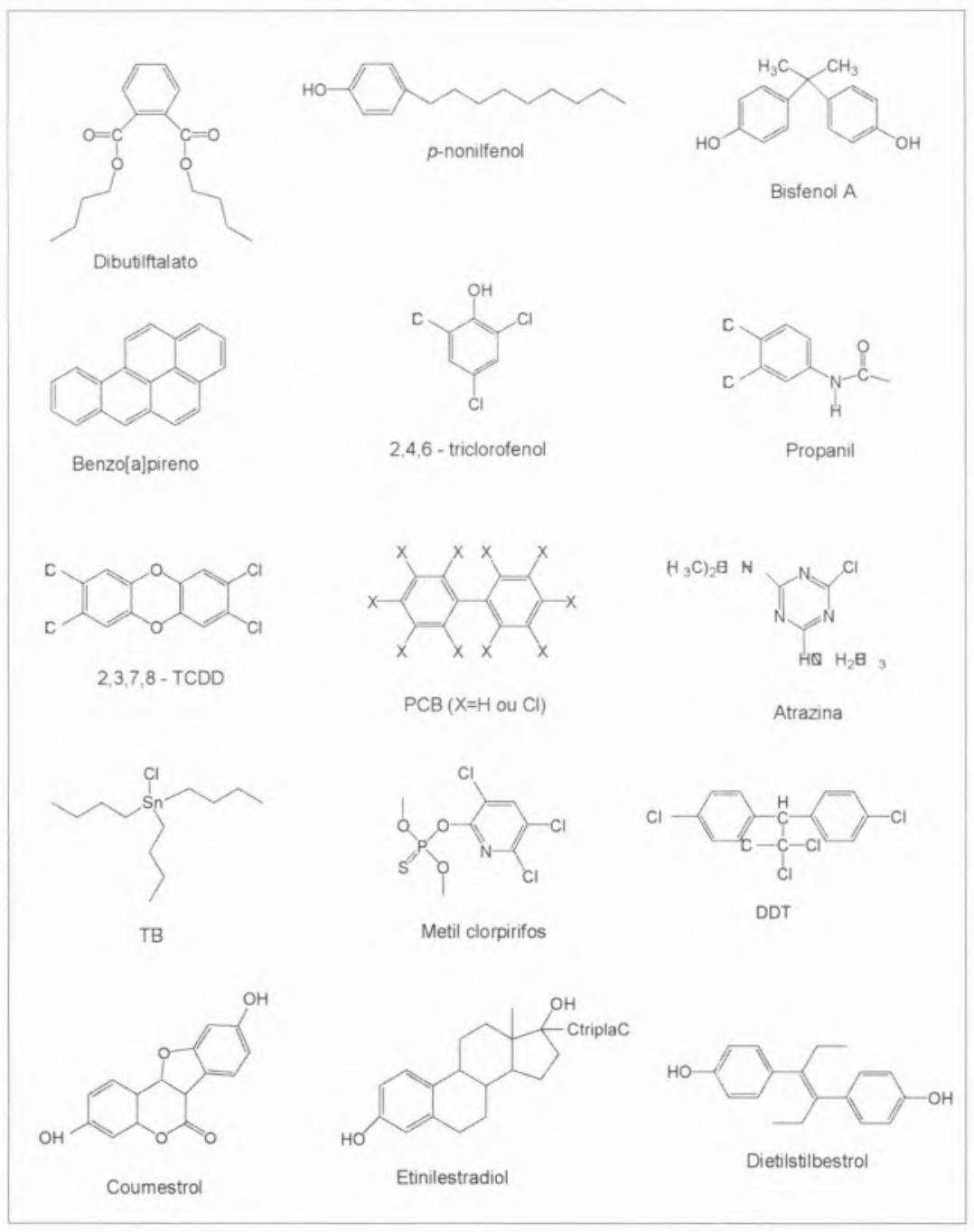

figura 2 Exemplo da estrutura química de alguns dos xeno-estrogénios mais comuns.

\section{Mecanismo de desregulação endócrina}

Os desreguladores endócrinos afectam o sistema endócrino e consequentemente as funções vitais nos seres vivos, imitando, bloqueando ou provocando o colapso das hormonas esteróides, sendo o mecanismo para esta desregulação complexo e diversificado. A alteração ou desregulação da função endócrina pode estar associada a interferências na síntese, secreção, transporte, ligação e acção ou eliminação das hormonas naturais do organismo, conduzindo a uma nova resposta hormonal, fraca ou forte, que resulta num sinal inexacto para o corpo. Algumas substâncias podem, por exemplo, imitar a acção das hormonas naturais levando o organismo a desencadear de um modo exagerado ou em tempo inapropriado a um estí- mulo falso, sendo o fenómeno designado por efeito agonista. Outras substâncias podem bloquear os receptores específicos a determinada hormona endógena, reduzindo ou anulando os estímulos em certas partes do organismo que normalmente Ihe são sensiveis, sendo este fenómeno denominado por efeito antagonista. Certos produtos farmacêuticos, como a pílula contraceptiva, são usados com o propósito justamente de causar intencionalmente algum destes efeitos, sendo o dietilstilbestrol considerado um bom exemplo de agonista superactivo.

A figura 3 ilustra de forma simplificada um receptor intracelular específico ao estradiol, sob acção agonista por parte do DDT e antagonista por parte de benzo[a]pireno, evidenciando desta maneira a relativa facilidade com que os xeno-estrogénios podem desencadear o mecanismo de desregulação endócrina.

Os principais factores que influenciam o modo de actuação dos desreguladores endócrinos no organismo relacionam-se com a natureza, concentração e tipo de interacção, tempo e altura de exposição, factores genéticos, especificidade dos tecidos, idade, sexo, entre outros.

Os efeitos adversos observados com maior frequência verificam-se ao nível da reprodução anómala, indução cancerígena, afectação neurológica e imunológica. Na vida selvagem, verifica-se uma diminuição da taxa de reprodução em muitas espécies de peixes (ex. salmão), um acréscimo da mortalidade precoce e nidificação com elementos do mesmo sexo entre determinado tipo de aves (ex. gaivotas), ressurgimento de casos de pseudohermafrodismo ou "imposex" em muitas espécies marinhas (ex. gastrópodes), malformações ao nível genital em répteis (ex. crocodilos), para além do declínio e extinção de diversas espécies costeiras (ex. ostras). Nas populações humanas, tem-se vindo a constatar que os desreguladores endócrinos estão associados ao decaimento na produção de esperma nos homens, ao aumento de casos de cancro sobretudo ao nível dos órgãos genitais, disfunções ao nivel dos ovários, infertilidade nas mulheres, malformações congénitas nos fetos, entre outras causas.

Há, no entanto, alguma dificuldade em demonstrar inequivocamente a relação directa entre a exposição e os efeitos causados por determinado(s) desregulador(es) endócrino(s), não se sabendo ainda se a combinação de várias destas substâncias pode potenciar as nefastas consequências observadas. A informação relativa à exposição é geralmente incompleta, os mecanismos de actuação não estão ainda totalmente esclarecidos e outros factores adicionais, nomeadamente a dieta alimentar, não podem ser negligenciados.

\section{Estratégias para monitorização de xenoestrogénios}

A União Europeia (EU), a Agência de Protecção Ambiental Norte-Amewricana 


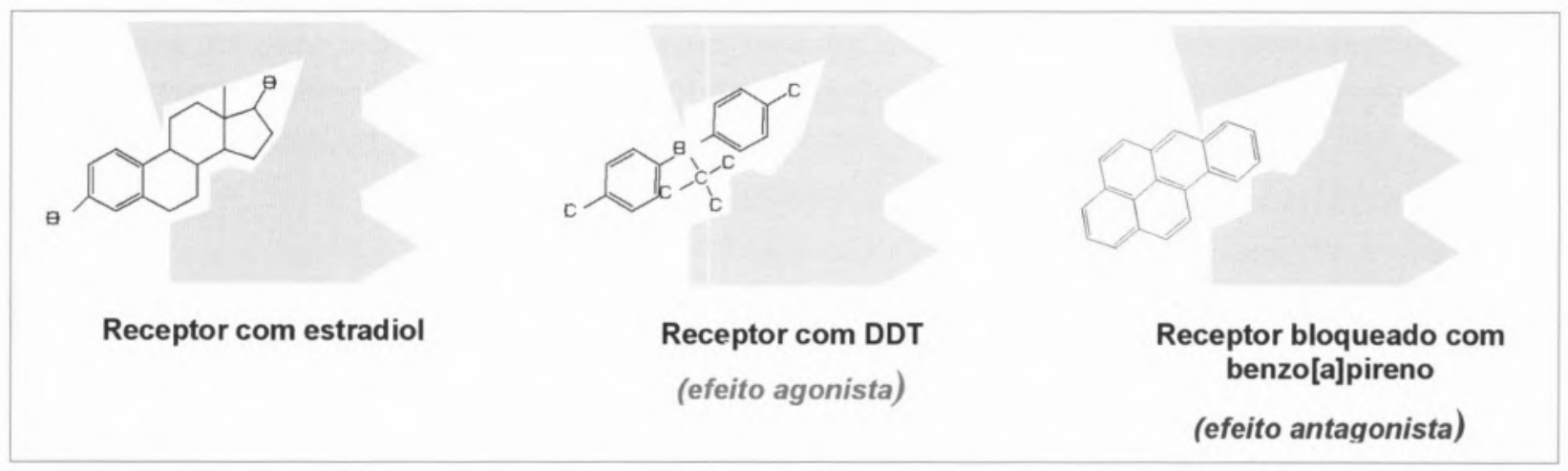

figura 3 Exemplo simplificado de um receptor intracelular especifico ao estradiol, ligado com DDT (efeito agonista) e obstruido com benzo[a]pireno (efeito antagonista), levando ambos os fenómenos à desregulação do sistema endócrino.

(EPA), a Organização Mundial de Saúde (OMS) e a Organização para a Cooperação e Desenvolvimento Económico (OCDE), evidenciam sérias preocupações com respeito à acção nefasta provocados pelos xeno-estrogénios. No sentido de esclarecer e solucionar o problema, estas instituições têm dinamizado e apoiado diversas iniciativas no âmbito da investigação e desenvolvimento a nivel internacional. $\mathrm{O}$ objectivo primordial é distinguir claramente, entre os potenciais desreguladores endócrinos, quais os que afectam mais drasticamente os ecossistemas, devendo ser banidos a curto prazo [4].

0 relatório de progresso sobre a estratégia comunitária em matéria de xeno-estrogénios (COM 706/1999), avaliou mais de 550 substâncias tendo classificado 118 com potencial actividade estrogénica comprovada [5]. Algumas destas substâncias apresentam um grande volume de produção ou persistência elevada, não estando ainda completamente restringidas ao abrigo da legislação europeia. No entanto, a lista de substâncias classificadas como possuindo actividade estrogénica, resultantes de diversos tipos de estudos, não pára de aumentar.

Na perspectiva aqui focada já se vislumbra a enorme importância na monitorização dos sistemas aquáticos, uma vez serem o principal veículo de dispersão ambiental dos xeno-estrogénios, podendo influenciar seriamente a cadeia alimentar.

As estratégias para monitorização e avaliação toxicológica dos xeno-estrogénios são genericamente baseadas na combinação de estudos de curto prazo que incluem a identificação da actividade es- trogénica in-vitro, com estudos de longo prazo que incluem a identificação e pesquisa dos efeitos da actividade estrogénica in-vivo e consequentemente, a avaliação do potencial risco para o Homem.

Do ponto de vista analítico, os métodos mais adequados para monitorização dos xeno-estrogénios em amostras ambientais incluem, genericamente, métodos biológicos e de separação [6-11]. Entre os primeiros, destacam-se principalmente os imunoensaios, cujo princípio é a produção de anticorpos e/ou receptores que se liguem especificamente a substâncias que apresentam actividade estrogénica. Com o intuito de análise vestigial em amostras ambientais, têmse desenvolvido inúmeros anticorpos e receptores específicos para os mais diversos tipos de poluentes químicos, evidenciando estes métodos elevada rapidez de screening.

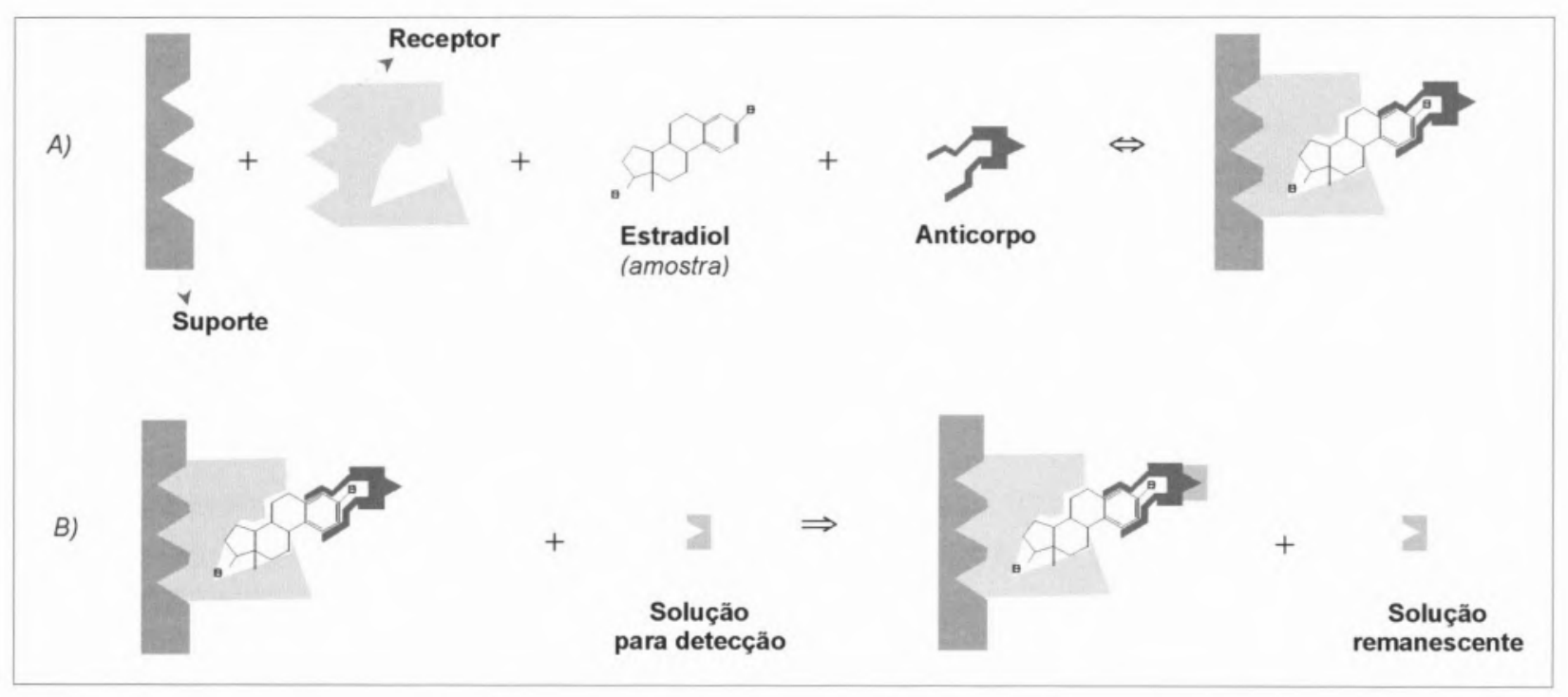

figura 4 Exemplo dos dois passos genericamente associados aos imunoensaios: A) Imobilização do receptor específico ao suporte, seguido de incubação após a adição da amostra contendo estrogénios e de anticorpos; B) Adição da solução adequada ao tipo de detecção pretendida. 
A figura 4 exemplifica os dois passos genericamente associados aos imunoensaios, sendo constituídos inicialmente pela imobilização do receptor específico a um suporte, seguido de adição da amostra em estudo contendo estrogénios e de anticorpos, ocorrendo então um período de incubação (1-4 h). Posteriormente, por adição de uma solução adequada ao tipo de detecção pretendida, procede-se a medidas de fluorescência (ex. ELRA: "Enzyme Linked Receptor Assay"), de actividade enzimática (ex. ELISA: "Enzyme Linked Immuno Sorbent Assay"), de radiação isotópica (ex. RIA: "Radio Immuno Assay"), entre outras [12].

Uma forma de controlar a exposição de algumas espécies de peixes (ex. carpa) a efluentes com propriedades agonistas, consiste na monitorização da vitelogenina nos machos, uma lipoproteína complexa que se encontra na gema do ovo e que, em circunstâncias normais, somente é detectável no plasma sanguíneo das fêmeas adultas. A determinação da vitelogenina pode ser acompanhada por ELISA, constituíndo deste modo um biomarcador para desreguladores endócrinos [13].

Outros métodos biológicos, nomeadamente as linhas celulares e os ensaios de DNA, são igualmente apontados na literatura como alternativas à monitorização de actividade xeno-estrogénica em amostras ambientais, embora no futuro os biosensores pareçam ser a aposta mais plausivel.

Não obstante os métodos biológicos serem rápidos, sensiveis, específicos, apresentarem limites de detecção relativamente baixos, da ordem das $0,1 \mathrm{ppb}$ e por vezes até pouco onerosos, não respondem eficazmente à identificação inequivoca dos xeno-estrogénios em questão, sobretudo se o principal objectivo for o de conhecer qual(is) o(s) tipo(s) de substância(s) existente(s) em amostras ambientais. Para obviar esta limitação, recorre-se usualmente a métodos de separação com particular incidência para as técnicas cromatográficas, electroforéticas e hifenadas, nos quais têm demonstrado ser bastante mais eficazes e versáteis na monitorização de um alargado grupo de xeno-estrogénios.

A necessidade premente de conhecer o tipo de xeno-estrogénios em amostras ambientais, não é em geral, totalmente compativel com a capacidade e o tempo de resposta dos métodos cromatográficos usuais, pelo que é imperativo investir em técnicas de screening que identifiquem o máximo número de xeno-estrogénios num só ensaio, designados por métodos multiresiduo, e que sejam aplicáveis em larga escala, para controlar o maior número de amostras possível. No entanto, a adopção de métodos multiresiduo que contemplem a análise de um grupo tão heterogéneo como é o caso dos desreguladores endócrinos, não é tarefa fácil, principalmente porque as diversas classes de compostos (ftalatos, pesticidas, alquifenóis, esteróides, PCBs, PAH's, etc.) apresentam propriedades físico-químicas muito diferentes ao nível da estabilidade, temperatura de ebulição (volatilidade), polaridade e estrutura molecular.

0 prévio tratamento das amostras ambientais para análise cromatográfica de xeno-estrogénios, particularmente amostras aquosas e sedimentos, tem-se direccionado no sentido de se adoptarem técnicas de extracção e concentração que permitam alcançar limites de detecção mais baixos, recuperar e isolar selectivamente analitos com diversa polaridade, reduzindo ao máximo a quantidade de solventes utilizados. Com este intuito, as técnicas de extracção em fase sólida (SPE: Solid-Phase Extraction) e micro-extracção em fase sólida (SPME: Solid-Phase Microextraction), baseadas em princípios de adsorção selectiva, têm vindo a substituir a extracção liquido-líquido convencional. Neste contexto, a SPE surge como a técnica mais abrangente e robusta a todo o tipo de xeno-estrogénios em simultâneo, muito selectiva e com possibilidade de analisar amostras ambientais em larga escala, fundamentalmente quando automatizada [14]. Possibilita a utilização de diversos tipos de fases estacionárias, permitindo extracção em fase sólida sequencial (SSPE) caso a gama de polaridade dos xeno-estrogénios em estudo seja acentuada. Apresenta fácil manipulação e permite igualmente a limpeza (clean-up) de potenciais interferentes das amostras mais sujas. Um passo de derivatização pode igualmente ser implementado sempre que analitos em particular o exijam, incrementando desta forma vantagens analíticas.

A cromatografia gasosa capilar especialmente quando acoplada à espectrometria de massa (CGC/MSD) apresenta-se como a técnica analítica mais evoluída, robusta, abrangente, reprodutível e sensivel, no sentido da monitorização de um alargado conjunto de xeno-estrogénios em amostras ambientais. A instrumentação actualmente disponivel alia a diminuição dos limites de detecção com

\footnotetext{
figura 5 Exemplo da análise por PTV-CGC/MSD(SIM) de um padrão contendo diversas classes de xenoestrogénios para um nivel de concentraçâo individual de aproximadamente $0,25 \mathrm{ng} / \mu \mathrm{L}$ CROMATOGRAFO - 6890 Agilent Technologies com amostrador automático (7683 Agilent Technologies) Injector: PTV; modo de "solvent vent"; $150 \mathrm{~mL} / \mathrm{min}(0,30 \mathrm{~min})$; $40,{ }^{\circ} \mathrm{C}(0,35 \mathrm{~min}) / 600{ }^{\circ} \mathrm{min}-1 / 320 .{ }^{\circ} \mathrm{C}(2 \mathrm{~min}) / 50 .{ }^{\circ} \mathrm{min}-1 / 200 .{ }^{\circ} \mathrm{C} ; 2 \mu \mathrm{L}$ Coluna: HP- 5 MS $(30 \mathrm{~m} \times 0,25 \mathrm{~mm} \times 0,25 \mathrm{~mm})$; He $(17,30 \mathrm{psi}$. "locked to methyl chlorpyrifos")

Forno: $70^{\circ} \mathrm{C}(2 \mathrm{~min}) / 25^{\circ} \mathrm{min}-1 / 150^{\circ} \mathrm{C}(0) / 3^{\circ} \mathrm{min}-1 / 200^{\circ} \mathrm{C}(0) / 8^{\circ} \mathrm{min}-$ $1 / 280^{\circ} \mathrm{C}(10 \mathrm{~min})$

ESPECTROMETRO DE MASSA - 5973N Agilent Technologies Modo SIM; i î̄es (m/2): 107, 149, 160, 161, 162, 182, 200, 201.
} 214,268 e $286 ; T_{\text {LT }}: 280^{\circ} \mathrm{C} ; T_{F}: 200^{\circ} \mathrm{C}$

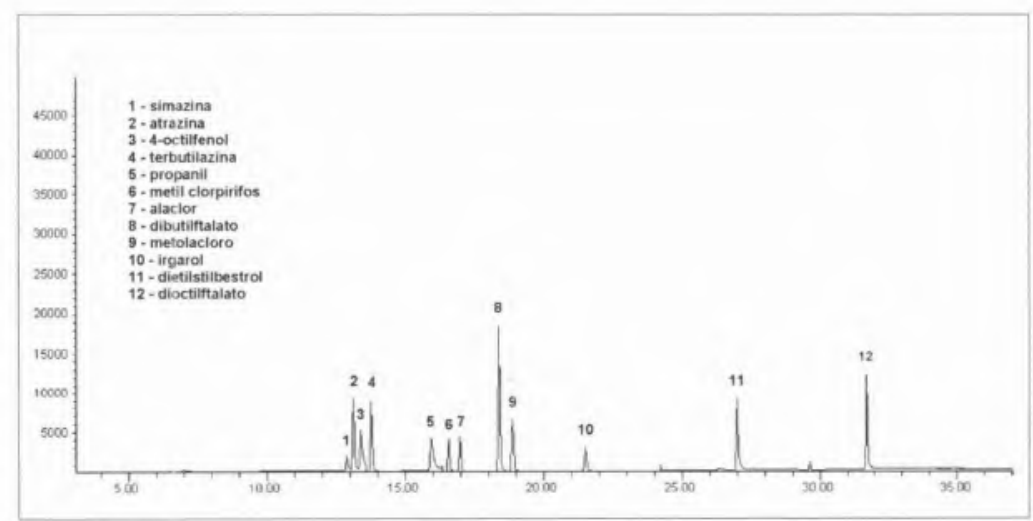


a adopção de injectores de temperatura programada (PTV) que possibilita injecçōes de grande volume (LVI), à excelente reprodutibilidade analítica através do controlo pneumático do gás de arrastamento (RTL: Retention Time Locking) e utilização de amostrador automático, bem como à elevada selectividade com recurso ao impacto electrónico quer no modo de varrimento (Full-SCAN), quer através da monitorização seleccionada de iões (SIM). Possibilita ainda a utilização da cromatografia gasosa rápida (fast-GC), onde o tempo analítico de um método optimizado pode ser diminuído drásticamente. A figura 5 exemplifica a análise por PTV-CGC/MSD(SIM) de um padrão contendo diversas classes de xeno-estrogénios monitorizados no modo SIM, onde é bem visível a elevada sensibilidade e selectividade evidenciadas para um nivel de concentracção individual de aproximadamente 0,25 $\mathrm{ng} / \mathrm{mL}$.

O teor de xeno-estrogénios geralmente observado em amostras ambientais, por vezes da ordem dos baixos ppts, requer automatismos que possibilitem a rápida monitorização por CGC/MSD. Actualmente, estão disponiveis ou podem ser construídas bibliotecas que conjugam para cada composto o tempo de retenção rigoroso com a respectiva informação espectral, nomeadamente a relação das abundâncias do correspondente ião alvo, geralmente o pico base e mais três iões qualificadores, para um dado método optimizado em particular. Esta informação quando combinada com software adequado, permite de um modo expedito e rápido o screening de amostras ambientais.

Tomando em linha de conta a presente abordagem, técnicas como a cromatografia líquida de alta eficiência e a electroforese capilar com detecção quer por rede de díodos (LC-DAD, CE-DAD) quer quando acopladas á espectrometria de massa (LC/MSD, CE/MSD) entre outras, com todas as vantagens que apresentam, ainda não se compadecem como alternativas a um conjunto tão diversificado de compostos, uma vez a sensibilidade entre outros aspectos limitativos não poderem ser negligenciados. São no entanto, poderosas ferramentas analíticas adicionais especialmente para análise ou confirmação de grupos restritos de xeno-estrogénios em particular.

Num futuro próximo, a aposta na eficiente monitorização dos xeno-estrogénios de amostras ambientais parece ser a combinação entre métodos biológicos, através de ensaios de imunoextracção que consistem no isolamento selectivo de classes restritas de xeno-estrogénios de amostras ambientais, com recurso à SPE contendo anticorpos muito especificos na constituição da fase estacionária ("immunosorbents"), e métodos cromatográficos.

\section{Que medidas devemos tomar}

Como nota final e tendo em linha de conta todas as implicações em termos de saúde pública, a OMS recomenda a prática das seguintes medidas no que concerne à alimentação, com o intuito de reduzir os riscos da exposição e bioacumulação humana aos desreguladores endócrinos:

- Reduzir a ingestão de óleos e gorduras, uma vez os xeno-estrogénios serem particularmente lipofilicos;

- Evitar cozinhar em recipientes plásticos por microondas ou guardar alimentos nos mesmos, de modo a prevenir a desagregação dos plasticizantes;

- Consumir alimentos isentos de resíduos de pesticidas;

- Verificar a origem do peixe, aves e outras carnes para consumo humano;

- Evitar ingerir água sem um prévio e apertado controlo analítico da qualidade.

\section{Bibliografia}

1. G.L. Zubey, W.W. Parson, D.E. Vance, Principles of Biochemistry, Wm. C. Brown Publishers, UK, 1995.

2. Louis J. Guillette, D. Andrew Crain, Environmental Endocrine Disruptors: An Evolutio- nary Perspective, Taylor \& Francis, New York, 2000.

3. Institute for Environment and Health, Environmental Oestrogens: Consequences to human health and wildlife. Institute for Environment and Health, University of Leicester, Leicester, UK, 1995.

4. The Working Group on Endocrine Disrupters of the Scientific Committee on Toxicity, Ecotoxicity and the Environment, CSTEE Opinion on Human and Wildlife Health Effects of Endocrine Disrupting Chemicals, with Emphasis on Wildlife and on Ecotoxicology Test Methods, 1999.

5. Comissão da Uniâo Europeia, Estratégia Comunitária em Matéria de Desreguladores Endócrinos - Substâncias suspeitas de Interferir com os sistemas hormonais dos seres humanos e dos animais, Relatório de Progresso, COM 706, 1999.

6. Oosterkamp A.J., Hock B., Seifert M., Irth H., (1997) Novel Monitoring Strategies for Xenoestrogens, Trends Anal. Chem., 16 (10) 544-553.

7. Sadik O.A., Witt D.M., (1999) Monitoring Endocrine-Disrupting Chemicals, Environ. Sci. Technol., 33 (17) 368A-374A.

8. Vanderlaan M., Watkins B.E., Stanker L., (1988) Environmental Monitoring by Immunoassay, Environ. Sci. Technol., 22 (3) $247-$ 254. Erickson B., (1998) Screening and Testing for Endocrine Disrupters, Anal. Chem., 70 528A-532A

9. Jimènez B., (1997) Environmental Effects of Endocrine Disruptors and Current Methodologies for Assessing Wildlife Health Effects, Trends Anal. Chem., 16 (10) 596-605. 10. Barceló D., (1993) Environmental Protection Agency and Other Methods for the Determination of Priority Pesticides and Their Transformation Products in Water, J. Chromatogr., 643 117-143.

11. Hennion M.C., Pichon V., Barceló D., (1994) Surface water analysis (trace-organic contaminants) and regulations, Trends Anal. Chem., 13 (9) 361-372.

12. Chard T., An Introduction to Radioimmunoassay and Related Techniques, Elsevier, Oxford, 1990.

13. Hansen P.-D., Dizer H., Hock B., Marx A., Sherry J., McMaster M., Blaise Ch., (1998) Vitellogenin - a biomarker for endocrine disruptors, Trends Anal. Chem., 17 (7) 448-451.

14. Barceló D., Sampling Handling and Trace Analysis of Pollutants Techniques, Applications and Quality Assurance, Elsevier, 2000. 


\section{Eur \\ European Journal of Inorganic Chemistry}

\section{Yourjournal}

First Impact Factor: 2.222

Rapid publication times especially for short communications

Now supported by ten national chemical societies (Belgium,

France, Germany, Greece, Hungary - together with the Hungarian

Academy of Sciences, Italy, The Netherlands, Portugal, Spain)

Authors' work exhibited on the cover

Attractive personal member subscription rates available;

see: www. EurJIC.com

More color

\section{European Journal of Inorganic Chemistry}

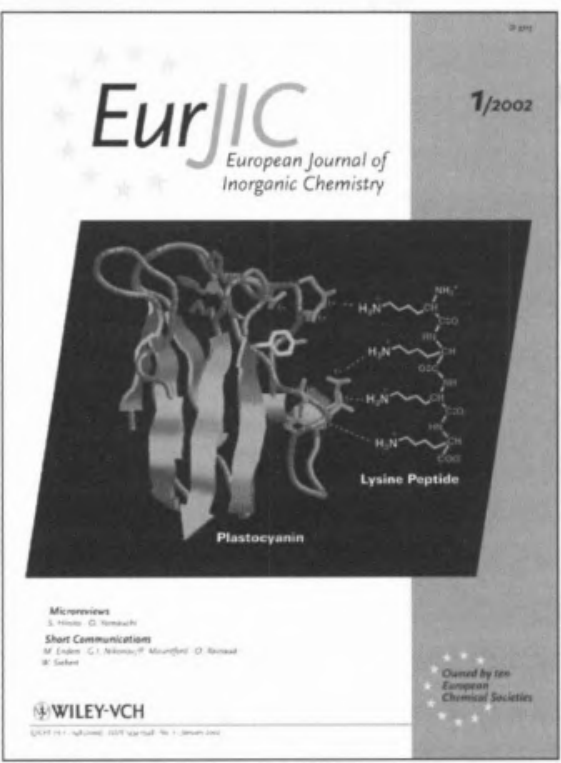

\section{Wiley-VCH}

200212 issues

ISSN Print 1434-1948

ISSN Electronic 1099-0682

The European Journal of Inorganic Chemistry publishes full papers and short communications on the entire spectrum of inorganic and organometallic chemistry. These contributions are supplemented by microreviews - introducing readers to one specific area of an author's research by means of a detailed overview of one selected topic.

Senior Editor: Ivano Bertini (Italy)

\section{FREE SAMPLE COPY}

The European Journal of Inorganic Chemistry is available online through Wiley InterScience. Visit Wiley InterScience (www.interscience.wiley.com) for complete details and see the FREE full text virtual sample copy.
Order Your Copy now:

Just copy, fill in and fax to: +49/(0)6201/606-172

\lrcorner Please send me a free sample print copy

Please enter our/my 2002 subscription to:

European Journal of Inorganic Chemistry

2002, ISSN Print 1434-1948

2002, ISSN Electronic 1099-0682 at the institutional rate*

\begin{tabular}{|c|c|c|}
\hline & print & electronic \\
\hline $\mathrm{Eu}$ & \lrcorner$\in 1868$ & $\sqsupset € 1868$ \\
\hline $\begin{array}{l}\text { rland } \\
\text { er }\end{array}$ & sFr 3258 & J sFr 3258 \\
\hline & JUS & 3. \\
\hline access. & print a & sca \\
\hline
\end{tabular}

For members of the owner societies from Belgium, France, Germany, Greece, Hungary, Italy, The Netherlands, Portugal and Spain, at the personal rate:

Europe print $\quad J \in 218$
J Switzerland $J$ sFr 458
All other

countries JUS\$ 248

Prices include postage and handling charges.

Please tick: $\square$ private $\square$ business

Name

Address

City/Postcode

Country

Membership-No.

Date/Signature

Please return this order to your local bookseller or to:

Customers in Germany, Austria and Switzerland:

Wiley-VCH Customer Service

P.O. Box 101161

D-69451 Weinheim, Germany

Phone: +49 (0) 6201-606147

Fax: +49 (0) 6201-606 172

e-mail: subservice@wiley-vch.de

Customers in all other areas:

John Wiley \& Sons, Ltd.

Journals Administration Department 1 Oldlands Way

Bognor Regis West Sussex, P022 9SA England

Phone: +44 (0) 1243-779 777

Fax: +44 (0) 1243-843 232

e-mail:cs-journals@wiley.co.uk

WWILEY-VCH 